\title{
The Effects of Amino Acids Enriched Del Nido Cardioplegia on Myocardial Leucocyte Accumulation and Ventricular Functions in Patients Undergoing Coronary Artery Bypass Grafting Surgery
}

\author{
Zeki Temizturk, MD, ${ }^{1}$ Davut Azboy, $M D,{ }^{2}$ Ayhan Uysal, $\mathrm{MD}^{2}$ \\ ${ }^{1}$ Department of cardiovascular Surgery, The Health Science University Elazig Research and Education Hospital, Elazig, Turkey; \\ ${ }^{2}$ Department of Cardiovascular Surgery, Firat University School of Medicine, Elazig, Turkey
}

\section{ABSTRACT}

Background: One of the main sources of ischemia/ reperfusion injury (IRI) and release of free oxygen radicals (FORs) during extracorporeal circulation (ECC) during cardiac surgery is neutrophils. In this study, we investigated the potential effects of our modification of del Nido cardioplegia (mDNC) (amino acids enriched del Nido cardioplegia) on myocardial polymorphonuclear leucocyte (PMNL) accumulation. We also compared the effects of our $\mathrm{mDND}$ and classical del Nido cardiplegia (cDNC) on ventricular contractile functions in coronary artery bypass grafting (CABG) surgery.

Patients and methods: Our study included 100 isolated CABG patients with similar characteristics, including age, gender, preoperative medications, diabetes, hypertension, and left ventricular ejection fraction (LVEF). The patients were divided into two groups. Amino acids supplemented del Nido cardioplegia (L-aspartate and L-glutamate at a dose of $13 \mathrm{milimol} / \mathrm{L}$ ) in 50 patients (study group, G1). In the remaining 50 patients, we used a classical del Nido cardioplegic solution (cDNC) (control group, G2). Myocardial Tru-Cut biopsy from the right ventricle was taken before the institution of ECC and after weaning from ECC in all patients. Cardiac troponine-I (cTn-I), tumor necrosis factor-alpha (TNF-Alpha), Pro-Brain Natriuretic Peptide (Pro-BNP), and lactate levels were measured pre- and postoperatively. Invasive monitoring was performed to provide the left ventricular functions in both groups in the operating room and noted by a blinded anaesthesiologist.

Results: Five patients died post-surgery (5\%) (two from SG and three from CG $(P=.67)$, due to low cardiac output syndrome or multiorgan failure. At the postoperative period, cardiac output $(\mathrm{CO})$ and stroke volume index (SVI) was higher in $\mathrm{mDNC}($ mean \pm SDS; $32.1 \pm 7$ versus $22.2 \pm 6.9$ $\mathrm{mL} / \mathrm{min} / \mathrm{m}^{2}(P<.001)$. CI was significantly higher in $\mathrm{mDNC}$

Received August 15, 2020; accepted August 27, 2020.

Correspondence: Prof. Omer Faruk Dogan, MD, Adiyaman University School of Medicine, Ataturk Street No:1, Adiyaman, Turkey, GSM; +905334813056 (e-mail: ofdogan@hacettepe.edu.tr). after surgery $\left(3.10 \pm 0.76\right.$ versus $2.40 \pm 0.30 \mathrm{~L} / \mathrm{min} / \mathrm{m}^{2}$ $(P=.002)$. Ten patients $(20 \%)$ in $\mathrm{mDNC}$ and 16 patients $(32 \%)$ in $\mathrm{cDNC}$ required inotropic support $(P<.001)$. The postoperative inotropic requirement was less in $\mathrm{mDNC}$ (6.1 $\pm 1.8 \mathrm{mg} / \mathrm{kg}$ versus $9.2 \pm 1.9 \mathrm{mg} / \mathrm{kg}, P<.004)$. Blood gas analyses from the coronary sinus showed that myocardial acidosis was more severe in the control group [pH $(0.10$ \pm 0.09 versus $0.054 \pm 0.001 ; P=.34)$ ]. Blood lactate levels were significantly high in the control group $(1.01 \pm 0.007$ $\mathrm{mmol} / \mathrm{L}$ versus $1.92 \pm 0.35 \mathrm{mmol} / \mathrm{L})(P=.22)$. No difference was found when compared with cardioplegia volume in the $\mathrm{mDNC}$ and $\mathrm{cDNC}$ groups $(\mathrm{mDNC}=990.00 \pm 385$ $\mathrm{mL}$ in $\mathrm{DNC}=960 \pm 240 \mathrm{~mL}, P=.070)$. An aortic crossclamp time in the $\mathrm{mDNC}$ and $\mathrm{cDNC}$ groups were $88.4 \pm$ $8.9 \mathrm{~min}$, and $93 \pm 11 \mathrm{~min},(P=.76)$, but cardiopulmonary bypass time was significantly low in $\mathrm{mDNC}(\mathrm{mDNC}=98.3$ $\pm 22.5 \mathrm{~min}, \mathrm{DNC}=126 \pm 19.5 \mathrm{~min}, P=.0020)$. TNF-Alpha and Pro-BNP levels in patients received $\mathrm{mDNC}$ were significantly low $(P=.022)$. Postoperative cardiac enzyme levels (creatine kinase-MB and high sensitive troponin-I) were significantly low in the mDNC group $(P=.0034)$. Myocardial biopsy results showed that myocardial PMNL accumulation was significantly high in the control group $(P=.001)$. The amount of inotropic agent use was significantly high in the control group $(P=.003)$. After weaning from ECC, the left ventricular stroke work index (LVSWI), cardiac index (CI), and heart rate (HR) were significantly high in the study group $(P=.032 ; P=.002 ; P=.01)$. Postoperative blood and blood products requirements were significantly low in the mDNC group $(P=.002)$. At pre-discharge echocardiography, the mDNC group demonstrated significantly higher ventricular ejection fraction $(37.9 \pm 4.3 \%$ and $29.7 \pm 3.8 \%$, respectively $(P=.003)$.

Conclusion: Our study findings show that glutamateaspartate supplemented del Nido cardioplegia significantly decrease myocardial PMNL accumulation with reduced release of biochemical markers, including cardiac troponinI, TNF-alpha, and Pro-Bnp. Our study results demonstrated that amino acids supplementation in del Nido cardioplegia has some advantages in $\mathrm{CABG}$ patients, including the decrease of perioperative myocardial infarction and increase significantly the left ventricular functions including ventricular SVI and CI. 
Table 1. Patient characteristics. Data are presented as mean $( \pm \mathrm{SD})$

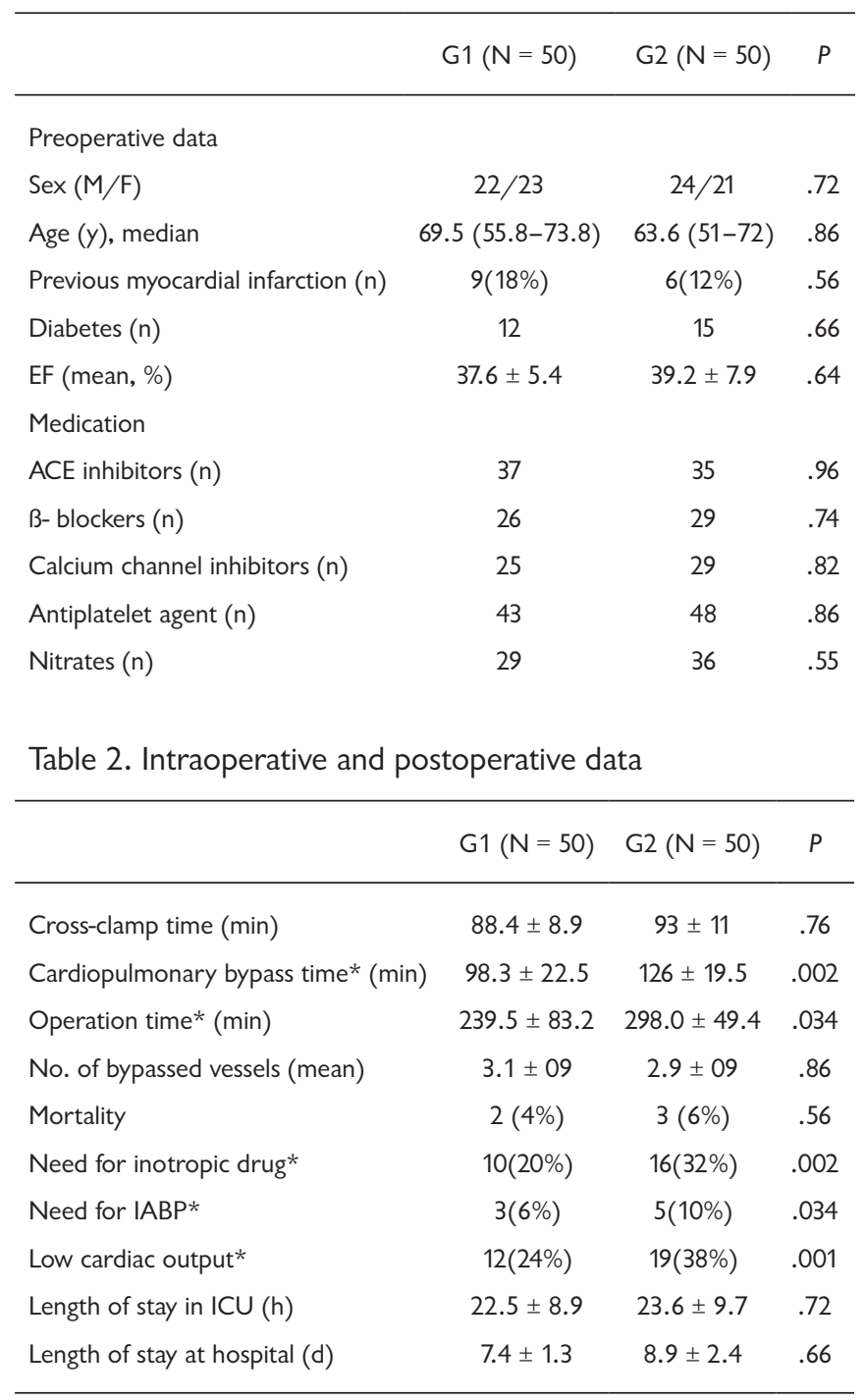

CPB: cardiopulmonary bypass; IABP: intra-aortic balloon counterpulsation; ICU: intensive care unit; $\mathrm{XC}$ : cross-clamp

\section{INTRODUCTION}

The main source of IRI and FORs in cardiac surgery is thought to be PMNL release some proteolytics enzymes and free radicals, which are derived from the coronary microvascular system and myocardium [Fiore 1998; Cohen 1999; Vinten-Johansen 2005]. Cytokines also stimulate the adhesion molecules on cardiomyocytes that allow neutrophils to adhere endothelial cells, and release IRI due to proteolytic enzymes [Ren 2003]. Neutrophils accumulation is a cause of myocardial damage as a result of diminished reperfusion area of the myocardium during ECC [Datz 1997]. Therefore, we hypothesize that if we may inhibit a myocardial polymorphonuclear leucocytes accumulation during surgery, this
Table 3. Cumulative doses and duration of inotropic agent(s). Data are presented as mean $( \pm \mathrm{SD})$

\begin{tabular}{lccc}
\hline & $\mathrm{G} 1$ & $\mathrm{G} 2$ & $P$ \\
\hline Dobamine $(\mathrm{mg})^{*}$ & $2370 \pm 305$ & $2170 \pm 309$ & .001 \\
Adrenaline $(\mathrm{mg})^{*}$ & $27 \pm 9.8$ & $49.3 \pm 14.7$ & .001 \\
Duration of inotrope(h)* & $19.2 \pm 7.9$ & $33.9 \pm 11.9$ & .01
\end{tabular}

may prevent myocardial failure resulting from inflammatory mediator release and FORs.

To reduce IRI and systemic inflammatory response, the authors suggested a different cardioplegic solution, such as tepid warm or cold cristalloid or blood cardioplegia, and administration techniques, such as antegrade, retrograde, or both [Datz 1997; Yazicioglu 2004; Buckberg 1995; Mallidi 2003; Chocron 1996; Hynninen 2001; Carrier 2002; Chambers 1996]. In addition, to inhibit IRI, volatile anaesthetics, anti-inflammatory agents, and some technical devices have been proposed [Hynninen 2001; Carrier 2002; Chambers 1996]. In previous investigations, the authors suggested heparin-coated circuits and steroids [Duman 2006], leukocyte filtration [Barner 1991], and nitric oxide donor compounds [Martin]. In addition, amino acids such as L-arginine [Hynninen 2001], insulin cardioplegia [Carrier 2002], aspartate alone, aspartate plus glutamate enriched cardioplegia [Duman 2006], and anaesthetic methods have been suggested to prevent or reduce IRI. However, a clear myocardial protective method has not yet been revealed. Because of the relatively small number of studies have shown, the effects of cardioplegic solutions for reducing the inflammatory response on myocardial reperfusion injury, there is no common consensus for optimal strategy to provide IRI during ECC [Martin 2003; Wilson 1993; Mullane 1985; Breda 1989; Mullane 1984].

The authors suggested that glutamate-aspartate as hydrophilic amino acids enriched cardioplegic solutions have enhanced myocardial protection [Vinten-Johansen 2005; Ren 2003]. Previous publications demonstrated that aspartate and glutamate significantly reduced the degree of cardiac necrosis macroscopically and histologically on pretreatment [Vinten-Johansen 2005; Ren 2003]. In another investigation, Bittle et al demonstrated an association between improved postischemic cardiac performance and increased production of alpha-ketoglutarate and succinate during glutamate treatment in rabbit hearts involving ischemia with reperfusion [Bittle 1983]. Published clinical data strongly support that these amino acids have myocardial protective properties [Arseni 1998; Pisarenko 1996; Lewis 2014]. In our previous study, we showed that glutamate-aspartate enriched cardioplegia has beneficial effects on ventricular functions in CABG patients [Duman 2006].

The hydrophilic amino acids might reduce cytoplasmic lactate levels, thereby deinhibiting glycolysis because they are substrates for the myocardial citric acid cycle. Glutamate and aspartate also move reducing equivalents from cytoplasm to 


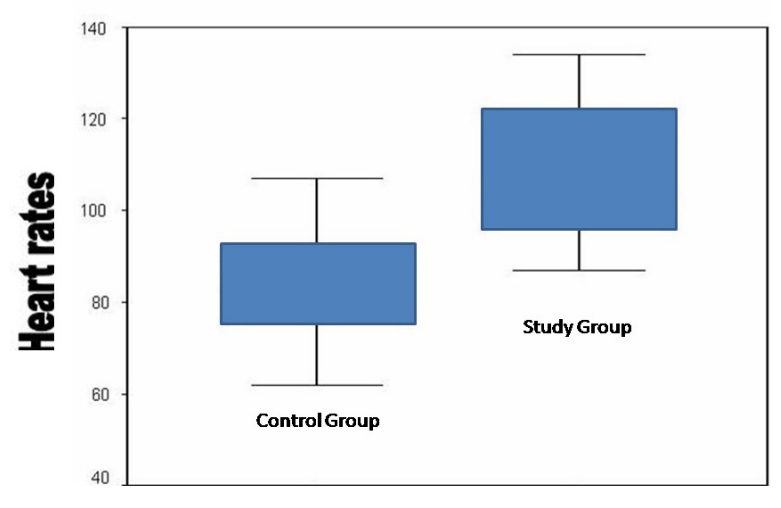

Figure 1. The heart rates in both groups. The mean heart rate is significantly higher at the second postoperative hour in the amino acid supplemented del Nido cardioplegia group.

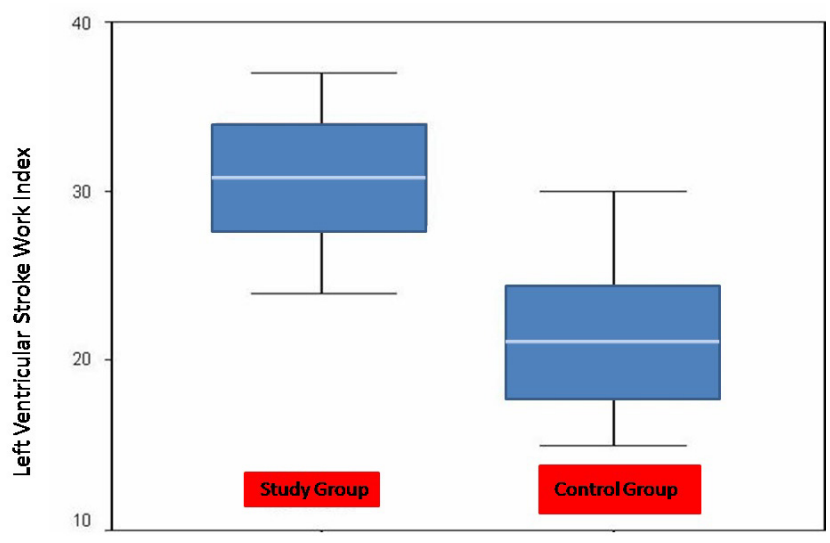

Figure 2. The left ventricular stroke work indices is significantly higher in the amino acid enriched cardioplegia group postoperatively.

mitochondria where they are necessary for oxidative phosphorylation and energy generation [Duman 2006].

To our knowledge, there is no investigation about the effect of L-glutamate and L-aspartate enriched DNC on quantitative myocardial white blood cell (WBC) accumulation and its hemodynamic outcomes. To research whether amino acids enriched blood cardiplegia decrease in myocardial PMNL accumulation, we used tepid modified DNC cardioplegia in 50 CABG patients with low left ventricular ejection fraction. For assessment of perioperative myocardial damage in the study group, we compared cardiac enzyme levels after surgery, TNF-alpha, Pro-BNP, and lactate levels in both groups. To evaluate the relationship between myocardial PMNL levels and the left ventricular contractile functions, we compared cardiac indices and left ventricular stroke work index.

\section{PATIENTS AND METHODS}

Following the approval of our institutional review board of ethics (Ahi Evran University, 2019-21/2019), informed

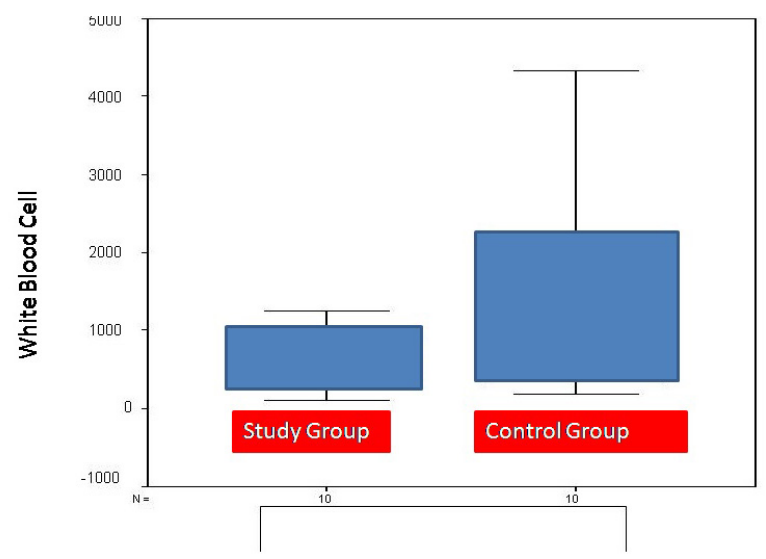

Figure 3. The white blood cell counts are significantly lower in the amino acid enriched del Nido cardioplegia group from the right ventricular biopsy materials.

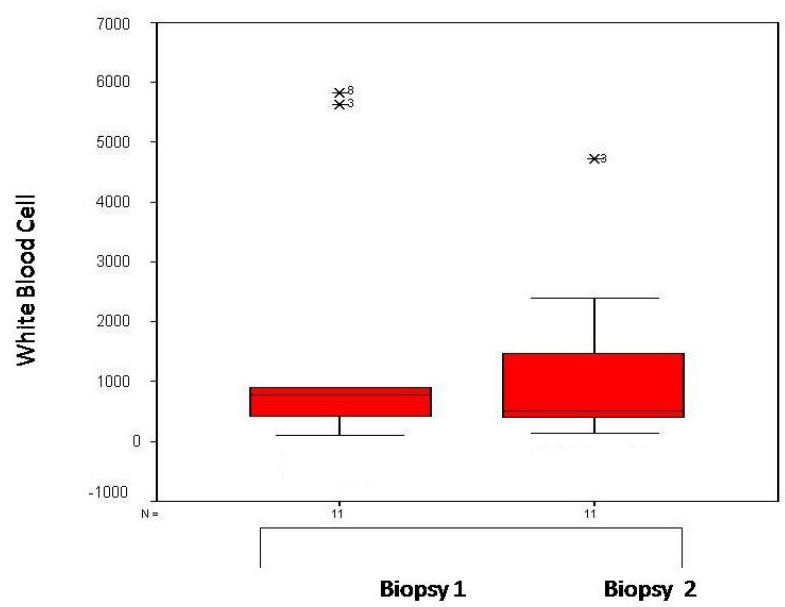

Figure 4. Same as Figure 3, the white blood cell counts are significantly lower in the amino acid enriched del Nido cardioplegia group from the right ventricular biopsy materials.

written consent was obtained from each patient. Onehundred consecutive isolated CABG patients with similar preoperative characteristics, including age, gender, myocardial functions, and additional disease, were included in the study.

Preoperative charecteristics of the patients and echocardiographic parameters are summarized in Table 1. Patients with severe valvular heart disease, chronic obstructive pulmonary disease, history of cardiac operation, and chronic renal or hepatic failure were excluded from the study. In addition, unstable angina or a history of myocardial infarction within three months prior to surgery, patients with active infection, leukocytosis or neutropenia or immunodeficiency were not included in this study.

All patients underwent surgical intervention on an elective basis. In G1 and G2, male and female ratios were identical. 
Table 4. Perioperative and postoperative haemodynamic data in both groups

\begin{tabular}{|c|c|c|c|c|}
\hline \multicolumn{5}{|c|}{ PCWP (mmHg) } \\
\hline G1 & $11.7(11.0-14.7)$ & $17.2 \dagger(13.2-19.0)$ & $14.0 ¥(13.0-16.0)$ & $12.3(11.2-15.0)$ \\
\hline \multicolumn{5}{|c|}{$\mathrm{Cl}\left(\mathrm{L} / \mathrm{min} / \mathrm{m}^{2}\right)$} \\
\hline G2 & $2.2(2.1-2.4)$ & $2.1(1.9-2.3)$ & $2.29 \pm 0.63$ & $2.40 \pm 0.30$ \\
\hline \multicolumn{5}{|c|}{ SVRI (dynes $/ \mathrm{cm}^{5} / \mathrm{m}^{2}$ ) } \\
\hline G1 & $2137(1922-2270)$ & $1931+(1730-2138)$ & $1754+(1561-2081)$ & $1710+(1482-1990)$ \\
\hline G1 & $2126(1824-2285)$ & 2016(1789-2190) & $2007(1785-2223)$ & $2008(1724-2285)$ \\
\hline
\end{tabular}

PCWP: pulmonary capillary wedge pressure; Cl: cardiac index; SVRI: systemic venous resistance index. Data are presented as median (IQR).*Different from the control group. $†$ different compared with baseline

The mean age and ventricular function were similar in both groups. The left ventricular ejection fractions were lower than $45 \%$ in both groups. We used amino acids supplemented del Nido cardioplegia via antegrade $(500-750 \mathrm{cc})$ and retrograde delivery $(150 \mathrm{cc}-250 \mathrm{cc})$ in 50 patients (study group; G1). In the remaining 50 patients, standard del Nido cardioplegia was used to obtain myocardial arrest. No difference was found when compared with cardioplegia volume in the $\mathrm{mDNC}$ and $\mathrm{cDNC}$ groups $(\mathrm{mDNC}=990.00 \pm 385 \mathrm{~mL}$ in $\mathrm{DNC}=960 \pm$ $240 \mathrm{~mL}, P=.070)$.

cTn-I, Pro-BNP, TNF-alpha levels were measured prior to operation (T0) and after surgery. The left internal thoracic artery, radial artery, and saphenous vein were used as bypass conduits in both groups. The mean number of distal anastomosis were $3.1 \pm 09$ versus $2.9 \pm 09(P=.86)$.

Study protocol: This study was designed to compare the efficacy of amino acid supplemented del Nido cardioplegia on myocardial accumulation of white blood cell and hemodynamics in CABG patients with low ejection fraction. Neither the ICU team nor the surgeons know which cardioplegia is being administered. The patients were divided into two groups: study group (G1) $(\mathrm{N}=50)$ and control group (G2) $(\mathrm{N}=50)$. Randomization was performed in the surgery room; a sealed, nontransparent protocol envelope was opened for each patient and the patient was accordingly assigned to a group. The surgeons did not inform the mixture of cardioplegia prepared by the anaesthesist in the operating theater.

After induction of anaesthesia using diazepam $(0.1-0.2 \mathrm{mg} /$ $\mathrm{kg})$, fentanyl $(3-5 \mu \mathrm{g} / \mathrm{kg})$, thiopenthal $(0.5-2.0 \mathrm{mg} / \mathrm{kg})$, and pancuronium bromide $(0.1 \mathrm{mg} / \mathrm{kg})$, anaesthesia was maintained with isoflurane (0.5\% to $1.0 \%$ ). During an ECC, propofol (2-4 $\mathrm{mg} / \mathrm{kg} / \mathrm{h})$ was given in addition to fentanyl $(1-2 \mu \mathrm{g} / \mathrm{kg})$. In all patients, a Swan-Ganz Thermodilution catheter was placed via the internal jugular vein for hemodynamic study. Peripheral venous blood was immediately labeled with Tecnesium-99m exametazime (HMPAO) under sterile conditions to obtain for PMNL counts, as described at the guideline before in Nuclear Medicine Laboratories [Martin]. Immediately after the white blood cell labeling procedure, the blood was injected back into the patients via a central vein just before the operation.

The first myocardial biopsy: After a midline sternotomy incision, an aortic and a single venous cannulation was performed. Coronary bypass conduits, including the left internal thoracic artery, were prepared. Pericardium was incised, and the first myocardial biopsy from the right ventricle was collected before the initiation of ECC, using a 14-gauge TruCut biopsy needle (B1). At the same time, the first whole blood samples for leucocyte counts were taken from the central venous line (L1).

ECC was instituted using a roller pump. The circuits were primed with $2000 \mathrm{~mL}$ of Ringer lactate solution. All operations were performed under moderate hypothermia (blood temperature $32^{\circ} \mathrm{C}$ ). GAETBC is prepared using $13 \mathrm{milimol} / \mathrm{L}$ $\mathrm{L}$-aspartate and L-glutamate by the anaesthesist. After an aortic cross-clamping, GAETBC was given antegradely at a dose of $10 \mathrm{ml} / \mathrm{kg}$ in G1 patients. A standard cold blood cardioplegia, consisting of a 4:1 dilution of blood to Plegisol® solution with addition of $\mathrm{KCl}$, was delivered antegradely at a dose of $10 \mathrm{ml} / \mathrm{kg}$ in G2. Retrograde cardioplegia (at a dose of $200 \mathrm{~mL}$ ) was given via coronary sinus cannulae after the completion of distal anastomosis in both groups. Cumulative dose of cardioplegia was noted by the anaesthesist for each patient.

To measure blood c-Tn-I, TNF-alpha, and Pro-BNP, blood samples were taken from central vein prior to induction of anaesthesia (T0), after the LITA anastomosis (T1), immediately after the release of aortic cross-clamp (T2), at the end of proximal anastomosis (T3), and 12 hours after surgery (T4). Blood lactate levels, which determine tissue hypoxia, were measured at the same time.

The second myocardial biopsy: After weaning from ECC, the second myocardial biopsies were collected from the right ventricle at least $4 \mathrm{~cm}$ far away from the first biopsy points (V2) (prior to protamine sulphate infusion). At the same time, second whole blood samples were obtained for leucocyte count $(\mathrm{L} 2)$. The biopsy materials from the right ventricle were weighted at the nuclear medicine laboratories 
Table 5. Preoperative and postoperative blood cTnl (ng/ml) and lactate levels

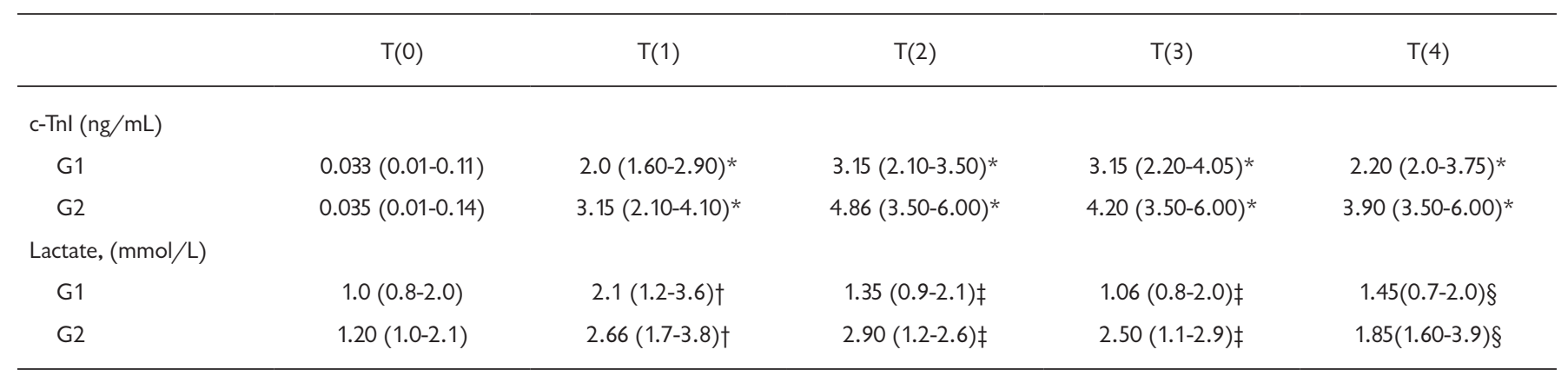

*Statistical significance, $P$ values between groups: intergroup comparison ( $P$ values). $\mathrm{T}(1): P=.001 ; \mathrm{T}(2): P=.003 ; \mathrm{T}(3): P=.004 ; \mathrm{T}(4): P=.004$

$\dagger, \ddagger$, $\S$ Statistical significance. Intergroup comparison. $\dagger P=.002 ; \ddagger P=.005 ; \ddagger P=.002 ; \S P=.004$

and counted by a Gamma Counter (DPC GAMBYT CR 10/20, LA.) and time/activity/gram measures were calculated, according to previous description by Datz et al. [Martin]. It was noted that the time period between the labeling of the leucocytes and counting of the biopsy materials were exactly the same for all subjects. Because the blood leucocyte levels were diluted during cardiopulmonary bypass for comparison of the patients' pre- and postoperative blood leucocyte levels, 'the corrected white blood cell' counts were recorded using this formula:

Corrected leucocyte level = Sample leucocyte level X Initial blood albumine level/Sample albumine level

For investigaton of the relationships between the myocardial leucocyte levels and cardiac hemodynamic status, we measured via Swan-Ganz catheter including heart rate, CI, CO, SVRI, and LVSWI. Baseline levels and postoperative myocardial markers were measured and compared. HR, intraaortic balloon pump use, the amount of inotropic drug(s) use, ICU duration, and hospitalization time for both groups also were compared.

Statistical analyses: Comparisons of the two groups were done by using the automated 17.0 SPSS program. For the comparison of hemodynamic measurements and enzyme levels and coronary sinus blood analyses, independent samples Student-T test was used. Before this comparison, for the indicating of variance differences, Levene test was used. Student t-test was used, according to the similar variance analyses. The data are presented as standard error of mean. A $P$-value of less than .05 was considered statistically significant. For the comparison of leucocyte counts of myocardial biopsy materials, paired sample test was used and if the results were less than 0.05 , they were considered statistically significant.

\section{RESULTS}

There was no mortality in either group. Estimated volume of cardioplegia was similar in G1 and G2, respectively. The duration of aortic cross-clamp time, ECC time, and operation time was compared. Aortic cross-clamp time was similar in both groups, however ECC time was significantly longer in the control group. Intraoperative data is summarized in Table 2. Cumulative doses and duration of inotropic agent(s) are summarized in Table 3 (data are presented as mean $\pm \mathrm{SD}$ ).

Hemodynamic measurements: The parameters of hemodynamic measurements were as follows: heart rate (HR), mean arterial pressure (MAP), central venous pressure (CVP), pulmonary capillary wedge pressure (PCWP), CO, CI, and LVSWI. All study parameters were compared in each case. Hemodynamic parameters were recorded at the end of the surgery, 12, and 24 hours after the CABG operations (Table 4). (Table 4) CI were measured via the thermodilution technique (Thermodilution Cath., Biosensors International; and Spectramed Hemo-Pro Cardiac Output Monitor, A Bol Health Care Lab, USA). The derived hemodynamic indices were as follows:

CI= Cardiac Output/Body Surface Area (LXmin-1Xm-2)

StrokeIndex $=$ Cardiac Index/HeartRate $(\mathrm{mLXmin}-1 \mathrm{Xm}-2)$

LVSWI= Stroke Index (MAP-PCWP) X $0.0136(\mathrm{gm} / \mathrm{m} 2)$

The myocardial white blood cell counts: There were two important findings of our study. The first one: There was a negative correlation between the white blood cell counts from the myocardial biopsies and myocardial acidosis, and free oxygen radical production. The second: There was a strong correlation between myocardial PMNL counts and LVSWI. In G2, prior to ECC, the mean WBC count was $705.40 \pm 395.40$ (max: 104.00; min: 1245.00); whereas, this mean level was $1669.30 \pm 1564$ (min: 190.00; max: 4321.00) after ECC. Intragroup analyses demonstrated that there was a significant difference was found $(P=.01)$. In 22 patients from $\mathrm{G} 2$, the WBC counts increased significantly. In 11 patients, PMNL count augmented more than $50 \%$. When compared with quantitative WBC counts of the ventricular biopsies in G1, no difference was found between pre- and post-bypass biopsies $(P=.372)$.

For each group, there were significant increments in the whole blood leucocyte counts of perioperative samples. In G2, pre-ECC leucocytes levels rose from 6007.64 \pm 1507.42 to $7852.45 \pm 2301.16(P=.034)$. Prior to ECC, myocardial PMNL count increased from $6556.10 \pm 1719.94$ to $8587.80 \pm 4280.24$ in $\mathrm{G} 1(\mathrm{P}=0.061)$. When compared with baseline and postoperative whole blood leucocyte counts, 
Table 6. Pro-BNP values in different times

\begin{tabular}{lccc}
\hline & G1 & G2 & $P$ \\
\hline T0 & $7.88 \pm 4.89$ & $9.10 \pm 6.54$ & .86 \\
T1* & $15.6 \pm 3.650$ & $36.84 \pm 9.55$ & .001 \\
T2* $^{*}$ & $21.06 \pm 4.4$ & $44.96 \pm 12.30$ & .007 \\
T3* $^{*}$ & $16.27 \pm 6.70$ & $39.50 \pm 12.90$ & .000 \\
T4* $^{*}$ & $24.50 \pm 11.04$ & $35.41 \pm 5.69$ & .002 \\
\hline
\end{tabular}

AF: atrial fibrillation, NT-proBNP: N-terminal natriuretic peptide. TO: preoperation time, T1: 1 hour after surgery, T2: 6 hours after the operation, T3: 12 hours after the operation, T4: 24 hour after the operation. $P<.05$ was evaluated at a level of significance

there was a significant increase in both groups $(P<.01)$. However, when we compared whole blood leucocyte levels in G1 and G2 in the postoperative period, no significant difference was found $(P=.86)$.

There was a significant difference between the two groups when comparing heart rates after the first postoperative hour. The mean heart rates were $83.6364 \pm 13.41 \mathrm{beat} / \mathrm{min}$. and $107.90 \pm 16$ beat $/ \mathrm{min}$. in G1 and G2, respectively (Figure 1). The heart rate was significantly low in G2 at the second postoperative hour $(P=.001)$. Our study findings showed there was a statistical difference when compared with LVSWI at the second postoperative hour in G1. While the preoperative left ventricular stroke work index was $33.90 \pm 2.64$ at the second postoperative hour in G1, this value was $21.50 \pm 4.25$ in G2 $(P<.001)$. The difference of LVSWIs were statistically significant when compared with both groups at the postoperative second hour $(P<.001)$ (Figure 2$)$. The mean myocardial leucocyte levels, whole blood leucocyte counts in both groups for each period are summarized in Figures 3 and 4.

Postoperative cumulative doses of inotropic agent requirements were significantly high in the $\mathrm{cDNC}$ group. Perioperative and postoperative hemodynamic data, including CI, PCWP, and SVRI, are summarized in Table 4. PCWP and SVRI were statistically higher postoperatively in G2. Myocardial acidosis caused by the aortic cross-clamping was found to be more severe in $\mathrm{G} 2[\mathrm{pH}(0.10 \pm 0.09$ versus $0.054 \pm 0.01](P=.034)$, and lactate levels were significantly high in $\mathrm{G} 2$ when comparing the groups $(1.01 \pm 0.007$ versus $1.92 \pm 0.35)(P=.22)$.

Preoperative cTn-I concentrations were similar in both groups. Seventy-five percent of patients were below the detectable limit; median concentration was $0.030 \mathrm{ng} / \mathrm{ml}$ among participants with detectable concentrations in G1 versus $64 \%$ and $20 \mathrm{ng} / \mathrm{L}$ in G2. Preoperative and postoperative blood cTn-I and lactate levels were significantly high in G2. cTn-I and lactate levels are summarized in Table 5. Intragroup analyses showed there were statistical differences in both groups after surgery and that these analyses were significantly higher in G2. Therefore, myocardial ischemia was more common in G2 patients than in G1. cTn-I levels rose following surgery peaking at six hours in both groups and
Table 7. White blood cell counts from the right ventricular biopsy materials and whole blood white cell levels in CG. These measurements are shown as the mean levels.

\begin{tabular}{lcccc}
\hline & Mean & $(\mathrm{SD} \pm)$ & Min & Max \\
\hline V(1) & 1525.00 & 2094.55 & 106.00 & 5825.00 \\
V(2) & 1172.00 & 1410.82 & 123.00 & 4713.00 \\
WBC PreECC & 6007.64 & 1507.47 & 3678.00 & 7658.00 \\
WBC PostECC & 7852.45 & 2301.16 & 4867.00 & 11937.00 \\
WBC PostOp 2 Hr & 11170.64 & 4532.08 & 5467.00 & 17468.00 \\
WBC Postop 12 Hr & 11176.00 & 4897.21 & 5920.00 & 18265.00 \\
WBC Postop 24 Hr & 12697.00 & 4561.00 & 5847.00 & 18736.00 \\
\hline
\end{tabular}

V1: first ventricular biopsy, V2: second ventricular biopsy, WBC: white blood cell

were, on average, $20-35 \%$ lower in G1 in all periods after surgery $(0.66 \pm 0.32$ versus $0.34 \pm 0.19)(P=.01)$.

Pro-BNP levels pre- and postoperative periods are summarized in Table 6. There was no difference comparing basal Pro-BNP levels between the groups. There were statistical differences between the groups in all periods after surgery. Blood Pro-BNP levels of G2 were higher than G1 patients after surgery. White blood cell counts after ventricular biopsy materials and whole blood white cell levels in the $\mathrm{cDNC}$ and $\mathrm{mDNC}$ groups are summarized in Tables 7 and 8 , respectively.

\section{DISCUSSION}

In the first three hours following $\mathrm{CPB}$, the heart does not use carbohydrate and lipid substrates. Four hours after beginning $\mathrm{CPB}$, cardiomyocyte does take up amino acids [Buckberg 1995; Chocron 1996; Hynninen 2001; Carrier 2002; Chambers 1996; Duman 2006]. Ischemic condition during an aortic cross-clamping, myocardium use glutamate and aspartate [Barner 1991; Martin; Martin 2003; Wilson 1993; Mullane 1985; Breda 1989; Mullane 1984]. In this situation, PMNLs, the endothelial nitric oxide may inactivate related to vasoconstriction. The release of FORs increases due to PMNL accumulation, and it stimulates the inactivation of nitric oxide by concomitant release of proteolytic enzymes from neutrophils [Bittle 1983; Arseni 1998; Pisarenko 1996; De Vecci 1997; Byrne 1992; Lewis 2014; Rowe 1983; Engler 1983]. To prevent IRI as a result of FORs release, the authors suggested anti-inflammatory agents, such as dexamethasone recently in open heart surgery [Uyar 2005; Mehta 1983; Sato 1997]. In addition, leukocyte filtration, different doses of corticosteroids, aprotinin, and heparin-coated ECC circuits, and nitric oxide donor compounds also have been proposed.

According to results of our study, preoperative preconditioning using L-glutamate and L-aspartate supplemented DNC can be used for protecting myocardial reperfusion injury in patients undergoing CABG to decrease leucocyte 
Table 8. White blood cell counts from the right ventricular biopsy materials and whole white blood cell levels in glutamate-aspartate enriched cardioplegia group.

\begin{tabular}{lcccc}
\hline & Mean & $(\mathrm{SD} \pm)$ & Min & Max \\
\hline V(1) & 705.40 & 395.40 & 104.00 & 1245.00 \\
V(2) & 1669.30 & 1564.79 & 190.00 & 4321.00 \\
WBC PreECC & 6556.10 & 1719.94 & 4009.00 & 8765.00 \\
WBC PostECC & 8587.80 & 4280.24 & 1098.00 & 17345.00 \\
WBC Postop 2 Hr & 10006.50 & 3969.49 & 4596.00 & 16343.00 \\
WBC Postop 12 Hr & 13186.50 & 5013.92 & 5287.00 & 20929.00 \\
WBC Postop 24 Hr & 13647.00 & 5506.80 & 5706.00 & 21750.00 \\
\hline
\end{tabular}

Levels are shown as mean levels. V1: first ventricular biopsy, V2: second ventricular biopsy, WBC: white blood

accumulation into the myocardium. Previous investigations have shown that glutamate-aspartate enriched cardioplegia increased myocardial performance in patients who underwent CABG [Carrier 2002; Chambers 1996; Duman 2006; Barner 1991]. As a result, mDNC provides coronary artery dilation and intramyocardial organelles activation and increases adenosine triphosphate (ATP) production. Glutamateaspartate supplementation may increase coronary artery flow and microcirculation and improve cardiac performance after surgery. Neurohormonal activation may increase resulting from amino acids supplementation in cardiac surgery [Lewis 2014; Rowe 1983; Engler 1983; Sato 1997].

We hypothesized there may be relationship between amino acids supplemention in del Nido cardioplegia and myocardial neutrophil accumulation. Therefore for testing of the effects of mDNC on myocardium, we used $\mathrm{mDNC}$ in our 50 CABG patients. Our study showed that amino acids supplemented del Nido cardioplegia significantly increased myocardial functions. In these patients, the mean level of myocardial leucocyte accumulation was significantly low. $\mathrm{CO}$ and CI were on average 0.75 and $1.20 \mathrm{~L} / \mathrm{min} / \mathrm{m}^{2}$ higher in the modified del Nido group than in the cDNC group at any time point especially within 24 hours after surgery. Myocardial enzyme release and TNF-alpha, Pro-BNP were lower at a 24 -hour interval. Mortality rate, mechanical ventilation, intensive care unit stay, and hospital time were similar when comparing both groups. Microscopic studies of myocardium showed that myofibrillar disarray and interfibrillar derangement were higher in the cDNC group. Another finding of our study included $\mathrm{mDNC}$ in our patients indicated a decrease in the rate of defibrillation after aortic cross-clamp release ( $8 \%$ versus $18 \%, P=.034)$.

We know that FORs and proteolytic agents, which are derived from the coronary microvascular system, increase during ECC [Fiore 1998; Cohen 1999; Vinten-Johansen 2005]. The main source of myocardial ischemia/reperfusion and the release of oxygen radicals in cardiac surgery is thought to be polymorphonuclear leucocyte, which may trigger proteolytics and destructive enzymes [Lewis 2014; Rowe 1983; Engler 1983; Uyar 2005; Mehta 1983; Sato 1997; Mizuno 1997; Hayashi 2000]. In addition, cytokines during ECC stimulate the adhesion molecules, which has negative effects of cardiomyocytes resulting from neutrophils that adhere to the endothelial cells of coronary microvascular systems and release IRI as a source of proteolytic enzymes [Datz 1997]. Therefore, some authors suggested amino acid supplementation in cardioplegic solutions [Carrier 2002; Arseni 1998, Pisarenko 1996; Byrne 1992; De Vecci 1997; Lewis 2014; Rowe 1983; Engler 1983]. To provide cardioprotection using amino acids such as glutamate and/or aspartate [Duman 2006; Arseni 1998; Pisarenko 1996; Byrne 1992; De Vecci 1997], L-Arginine has been added to improve anaerobic formation of intracellular organelles coupled with succinate and alpha-ketoglutarate formation with the inhibition of glycolytic flux [Mizuno 1997]. During reperfusion, both amino acids replenish the malate-aspartate shuttle reactants, thereby facilitating glucose oxidation [Lewis 2014; Rowe 1983; Engler 1983]. Habazetl et al showed the enhancement of the leukocyte-endothelial cell interaction in collecting venules of skeletal muscle by protamine [Habazetl 1997].

Previous investigation demonstrated that intracellular concentrations of branched chain amino acids (leucine, valine, and isoleucine) stimulated the formation of acetyl-CoA and succinyl-CoA and, thus, recovery of oxidative metabolism [Sato 1997]. Methionine and cysteine may force the contraction via methylation of phospholipids and the sarcoplasmic reticulum [Hayashi 2000; Tomoeda 1999]. Intracellular high concentrations of histidine provide antioxidants which is a scavenger of oxygen and hydroxyl radicals during an anaerobic energy formation.

Aprotinin and sodium nitroprusside pretreatment, leukocyte filtration, and heparin-coated ECC circuits decrease IRI, reduce the inflammatory response, and improve postoperative cardiac function in CABG patients [Bolling 1997; Fukushima 1994; Suzuki 1998; Ichihara 1994; Sawa 1994]. Corticosteroids or histidine were used to reduce ECC induced systemic inflammatory response in patients undergoing cardiac surgery who were pretreated with dexamethasone. Unfortunately, there is no common consensus yet about the optimal cardioplegic solutions and/or delivery method for myocardial protection, during ischemic arrest and reperfusion injury after aortic declamping in the literature.

Our study proposed that amino acids (aspartate, glutamate, leucine, taurine, or L-arginine) may be important for cardiac metabolism for reducing myocardial leucocyte accumulation. Glutamate and $\alpha$-ketoglutarate are interconvertible by transamination [Duman 2006; Pisarenko 1996; Byrne 1992; De Vecci 1997; Lewis 2014; Rowe 1983; Engler 1983; Uyar 2005; Mehta 1983; Sato 1997]. Glutamatic acid may enter the Krebs cycle in myocardial nitrogen metabolism [Habazetl 1997; Tomoeda 1999; Bolling 1997; Fukushima 1994]. Glutamate may be amidated to transport amine groups out of the cells. Thus, glutamate is a neurotransmitter that may interfere with normal function of the nervous system and some myocardial and end-organ side effects. Catabolisation of amino acids in the heart may provide energy recovery [Uyar 2005; Mehta 
1983; Sato 1997; Tomoeda 1999; Bolling 1997]. Habazetl et al showed the important role of amino acids use in the failing heart [Wilson 1993]. Adding amino acids has improved postischemic myocardial metabolism, including the function of complex of glutamate. This may be converted to ATP without molecular oxygen. Alpha-ketoglutarate also may participate in an aminotransferase reaction, with aspartate generating oxaloacetate which is metabolized with the generation of ATP. Therefore, we and other authors hypothesized that amino acids enriched cardioplegia may improve myocardial functions resulting from the decrease of myocardial infarction and pulmonary effects.

There are relatively small number of investigations about the use of amino acids enriched cardioplegia to protect inflammatory response on myocardial reperfusion injury [Carrier 2002; Chambers 1996; Duman 2006; Barner 1991]. A recent study [Duman 2006] and other previous investigations [Martin 2003; Wilson 1993; Mullane 1985; Breda 1989; Mullane 1984] showed that glutamate-aspartate-enriched cardioplegia has some beneficial effects on ventricular functions in CABG surgery.

To investigate whether there was a relationship between clinical parameters and myocardial functions, we performed myocardial biopsy from true-cut biopsy to assess myocardial PMNL levels in all patients. In order to investigate myocardial leucocyte accumulation and its effects on IRI in patients undergoing cardiac surgery, different leucocyte counts between the aortic root and coronary sinus blood, the authors investigated leucocyte specific myeloperoxidase enzyme levels, lipid peroxidation, and levels of malondialdehyde from coronary sinus blood [Bittle 1983; Arseni 1998; Pisarenko 1996; Byrne 1992; De Vecci 1997; Lewis 2014; Rowe 1983; Engler 1983].

To the best of our knowledge, we demonstrated the effects of amino acid enriched del Nido cardioplegia on quantitative PMNL accumulation into the myocardium in cardiac surgery for the first time. Previous studies have shown that leucocytes, which migrate to the myocardium during myocardial ischemia, were sources of FORs. But the authors did not investigate myocardial leucocyte counts [Bittle 1983; Pisarenko 1996; Byrne 1992; De Vecci 1997; Lewis 2014; Rowe 1983; Engler 1983; Uyar 2005; Mehta 1983; Sato 1997; Mizuno 1997]. Because leucocytes are among the main causes of myocardial damage by release of their lisosomal enzymes and by creating capillary plugs resulting in intramyocardial "no reflow phenomenon" [Uyar 2005; Mehta 1983; Mizuno 1997; Hayashi 2000; Habazetl 1997], we investigated leucocyte counts using a radionuclide method in our study.

The substrates, such as ATP, glucose and arginine, were proposed for preparing cardioplegic solution to provide myocardial energy during ischemia [Yazicioglu 2004; Buckberg 1995; Mallidi 2003; Chocron 1996; Hynninen 2001; Carrier 2002]. Kronon et al demonstrated that a warm glutamateaspartate enriched reperfusate reduced the reperfusion injury resulting in improved myocardial function and metabolic recovery in hypoxic neonatal hearts [Kronon 2000]. The clear mechanism of the effects of amino acid enriched cardioplegia on myocardial protection is not yet known. They investigated biochemical analyses during amino acid supplementation, and it improved recovery of intramyocardial ATP.

We therefore investigated the effect of $\mathrm{mDNC}$ on myocardial white blood cell counts in the perioperative period. Our study demonstrated that amino acids supplementation appears to be cardioprotective, resulting from decreasing PMNL accumulation into the myocardium. In addition, our study results showed L-glutamate and L-aspartate enriched cardioplegia may decrease myocardial enzymes release which markers of myocardial ischemia, Pro-BNP and TNFalpha levels. Therefore, myocardial performance in CABG patients, who received amino acids supplemented cardioplegia, may be enhanced. Our study showed an average reduction of $20-25 \%$ c-Tn-I and lactate levels and $30-42 \%$ TNFalpha after surgery.

According to our study, to inhibit leucocyte accumulation into the myocardium, preoperative preconditioning using L-glutamate and L-aspartate enriched DNC infusion may be used to prevent myocardial reperfusion injury in patients undergoing $\mathrm{CABG}$. It reduces endothelial adherence of leucocyte $\mathrm{mDNC}$ and may provide coronary artery dilation and intramyocardial organelles, such as mitocondrial activation as a result of adenosine triphosphate (ATP) production. Glutamate-aspartate enriched cardioplegia may also increase coronary artery flow, microcirculation circulation, enhance cardiac performance, and neurohormonal activation in CABG patients.

The main difference of our study is that we first showed myocardial leucocyte counts quantitatively. Secondly, we showed myocardial leucocyte depletion as an effect of glutamate-aspartate enriched cardioplegia infusion.

In our clinical setting, leucocyte labeling is used for detecting acute or chronic sites of inflammation or infections. For the first time in literature, we introduce a new way of using a leucocyte labeling technique as well as a new method for assessing the neutrophile accumulation quantitatively into the myocardium by counting them directly inside the myocardial tissue. In order to count the leucocyte accumulation in the myocardium during the ischemic period, we labeled the leucocytes by Tc $99 \mathrm{~m}-\mathrm{HMPAO}$ which does not affect the migration, chemotaxis, adhesion, and superoxide generation of labeled cells.

The biopsy procedure did not cause damage to the myocardium of the right ventricle. All the biopsies were collected with same kind of biopsy needle, and the tissue volumes were identical. Also, the weights were measured to be similar at the nuclear medicine laboratories. Second biopsies were collected before the administration of protamine sulphate as injection of protamine is shown to affect leucocyte kinetics [Fukushima 1994; Suzuki 1998]. The reason for collecting second biopsies at least $4 \mathrm{~cm}$ away from the first ones was to avoid the traumatic proinflammatory mediator response, which might stimulate the migration of the leucocytes to the biopsy point.

Following the ECC, there was a slight increase in the whole blood leucocyte levels; these were not statistically significant in either group. On the other hand, the leucocyte counts of biopsy materials of G1 were found to decrease 
significantly following ECC, whereas there were significantly increased counts with G2 patients. These results show that there is a leucocyte accumulation in the myocardium following cardioplegia infusion independent from the rise of circulating leucocytes.

There were significant differences between clinical outcomes of both groups when comparing heart rates, PVRI, CI, and LVSWIs of G1 patients in the postoperative period. As LVSWI is a calculated value reversely proportional with heart rates, the reason for significant decrease of LVSWIs of CG while the cardiac indices were high in G1 at the same period of time, was probably the significant increase of heart rates. Additional inotropic agents used, such as dobutamine or adrenaline and the amount of additional inotropic administration in $\mathrm{cDNC}$ group, was higher perioperatively.

\section{CONCLUSION}

Amino acids supplementation in cardioplegic solution may be used to prevent myocardial PMNL accumulation during CABG surgery. Amino acids may protect myocardial impairment, resulting from the increase of nitric oxide which improves coronary blood flow by decreasing leukocytes adhesion. Therefore, adhesion of leucocytes in the coronary endothelial surface during ECC decreases the reperfusion injury and may improve ventricular functions, and inhibit myocardial acidosis after IRI. In our opinion, we need other studies to confirm these effects of mDNC on myocardial white blood cell counts. Leucocytes accumulation into the myocardium in patients with poor left ventricles or longer ischemic periods may cause major clinical disturbances and affect the patients' clinical outcomes. We suggest glutamate-aspartate enriched del Nido cardioplegia as a cheap method to prevent leucocyte accumulation into the myocardium.

\section{STUDY LIMITATIONS}

We do not know whether the cardioplegia solution has a balanced distribution in patients with coronary artery disease. Thus, the effect of amino acids supplemented del Nido cardioplegia may be investigated in patients with normal coronary arteries undergoing cardiac valvular surgery. The study is constituted from limited patients with poor ventricular functions. Therefore, we need a large number of patients who are undergoing cardiac valvular surgery for congenital heart disease.

\section{REFERENCES}

Arseni M. 1998. Potential Cardiovascular Applications of Glutamate, Aspartate, and Other. Amino Acids. Clin. Cardiol. 21,620-24.

Barner HB. 1991. Blood cardioplegia: a review and comparison with crystalloid cardioplegia. Ann Thorac Surg. 52:1354-67.

Bittle JA, Shine KI. 1983. Protection of ischemic rabbit myocardium by glutamic acid. Am J Physiol. 245:406-12.
Bolling KS, Halldorsson A, Allen BS, Rahman S, Wang T, Kronon M, Feinberg H. 1997. Prevention of the hypoxic reoxygenation injury with the use of a leukocyte-depleting filter. J Thorac Cardiovasc Surg. 113: 1081-90.

Breda MA, Drinkwater DC, Laks H, Bhuta S, Corna AF, Davtyan HG, Chang P. 1989. Prevention of reperfusion injury in the neonatal heart with leukocyte-depleted blood. J Thorac Cardiovasc Surg. 97: 654 -/65.

Buckberg GD, Beyersdorf F, Allen BS, Robertson JM. 1995. Integrated myocardial management: background and initial application. J Card Surg. 10:68-89.

Byrne JG, ppleyard RF, Lee CC, Couper GS, Scholl FG, Laurence RG, Cohn LH. 1992. Controlled reperfusion of the regionally ischemic myocardium with leukocyte-depleted blood reduces stunning, the no-reflow phenomenon, and infarct size. J Thorac Cardiovasc Surg. 103: 66-/72.

Carrier M, Pellerin M, Perrault LP, Bouchgard D, Page P, Searle N, et al. 2002. Cardioplegic arrest with L-taurin improves myocardial protection: results of a prospective randomized clinical trial. Ann Thorac Surg. 73:837-41.

Chambers DJ, Haire K, Morley N, Fairbanks L, Strumia E, Young CP, et al. 1996. St. Thomas' Hospital cardioplegia: enhanced protection with exogenous creatine phosphate. Ann Thorac Surg. 61:67-75.

Chocron S, Alwan K, Toubin G, Clement F, Kaili D, Taberlet C, et al. 1996. Crystalloid cardioplegia route of delivery and cardiac troponin release. Ann Thorac Surg. 62:481-5.

Cohen G, Borger MA, Weisel RD, Rao V. 1999. Intraoperative myocardial protection: current trends and future perspective. Ann Thorac Surg. 68:1995-2001.

Datz FL, Seabold SL, Brown ML, et al. 1997. Society of Nuclear Medicine, Procedure guideline for technetium-99m exametazime (HMPAO) labeled leukocyte scintigraphy for suspected infection/inflammation. Journal of Nuclear Medicine. 38; 987-990.

De Vecci E, Paroni R, Pala MG, Di Credica G, Agape V, Gobbi C, Bonini PA, Paolini G, Grossi A. 1997. Role of leukocytes in free radical production during myocardial revascularization. Heart. 77: 449-/55.

Duman U, Dogan OF. 2006. Transient beneficial effects of glutamateaspartate-enriched cardioplegia on ventricular functions in coronary artery bypass grafting. J Card Surg. 21(5):523-5.

Engler RL, Schmid-Schonbein GW, Pavelec RS. 1983. Leucocyte capillary plugging in myocardial ischemia and reperfusion in the dog. Am J Pathol. 111:98.

Fiore AC, Swartz MT, Nevett R, Vieth PJ, Magrath RA, Sherrick A, Barner HP. 1998. Intermittent Antegrade Tepid Versus Cold Bloob Cardioplegia in Elective Myocardial Revascularization. Ann Thorac Surg. 65:1559-65.

Fukushima N, Shirakura R, Nakata S, Kaneko M, Miyagawa S, Naka Y, Chang JC, Matsumiya G, Nakano S, Matsuda H. 1994. Study of efficacies of leukocyte-depleted terminal blood cardioplegia in 24-hour preserved hearts. Ann Thorac Surg. 58: 1651-56.

Habazetl H, Martinek V, Vollmar B. 1997. Enhancement of the leukocyte-endothelial cell interaction in collecting venules of skeletal muscle by protamine. J Thorac Cardiovasc Surg. 113:784-91.

Hayashi Y, Sawa Y, Nishimura M, Ichikawa H, Kagisaki K, Ohtake S, Matsuda H. 2000. Clinical evaluation of leukocyte-depleted blood cardioplegia for pediatric open heart operation. Ann Thorac Surg. 69: 1914 $-/ 19$.

Hynninen M, Borger MA, Rao V, Weisel RD, Christakis GT, Carroll 
Cheng DC. 2001. The effect of insulin cardioplegia on atrial fibrillation after high risk coronary bypass surgery: a double-blinded, randomized controlled trial. Anesth Analg. 92:810-6.

Ichihara T, Yasuura K, Maseki T, Matsuura a, Miyahara K, Ito T, Kato S, Mizuno S, Tamaki S, Seki A. 1994. The effects of using a leukocyte removal filter during cold blood cardioplegia. Surg Today. 24:966-72.

Kronon MT, Allen BS, Rahman S, Wang T, Tayyab NA, Bolling KS, Ilbawi MN. 2000. Reducing postischemic reperfusion damage in neonates using a terminal warm substrate-enriched blood cardioplegic reperfusate. Ann Thorac Surg. 70:765-70.

Lewis M, Littlejohns B, Lin H, Angelini GD, Suleiman MS. 2014. Cardiac taurine and principal amino acids in right and left ventricles of patients with either aortic valve stenosis or coronary artery disease: the importance of diabetes and gender. SpringerPlus. 3:523.

Mallidi HR, Sever J, Tamariz M, Singh S, Hanayama N, Christakis GT, et al. 2003. The short-term and long-term effects of warm or tepid cardioplegia. J Thorac Cardiovasc Surg. 125:711-20.

Martin J, Benk C. Multimedia Manuel of Cardiothoracic Surgery. Blood Cardioplegia.

Martin J, Krause M, Benk C, et al. 2003. Blood Cardioplegia filtration Perfusion. 18:75-80.

Mehta JL, Nichols WW, Mehta P. 1983. Neutropils as potential participants in acute myocardial ischemic myocardial injury Am Heart J. 106:8-13.

Mizuno A, Baretti R, Buckberg GD. 1997. Endothelial stunning and myocyte recovery after reperfusion of jeopardized muscle. A role of L-Arginine blood cardioplegia. J Thorac Cardiopvasc Surg. 113:379-89.

Mullane K, Kraemer R, Smith B. 1985. Myeloperoxidase activity as a quantitative assessment of neutrophil infiltration into ischemic myocardium. J Pharmacol Methods.14:157-67.

Mullane KM, Read N, Salmon JA. 1984. Role of lucocytes in acute myocardial infarction in anesthetized dogs: Relationship to myocardial salvage by anti-inflammatory drugs J Pharmacol Exp Ther. 228:510-22.

Palatianos GM, Balentine G, Papadakis EG, Triantafillou CD, Vassili MI, Lidoriki A, Dinopoulos A, Astras GM. 2004. Neutrophil depletion reduces myocardial reperfusion morbidity Ann. Thorac. Surg. 77(3): 956-61.
Pisarenko OI. 1996. Mechanisms of myocardial protection by amino acids: facts and hypotheses. Clin Experimen Pharma \& Physio. 23:627-33.

Ren G, Dewald O, Frangogiannis NG. 2003. Inflammatory mechanisms in myocardial infarction. Curr Drug Targets Inflamm Allergy 2: 242-256.

Roth M, Kraus B, Scheffold T, Reuthebuch O, Klövekorn WP, Bauer EP. 2000. The effect of leukocyte-depleted blood cardioplegia in patients with severe left ventricular dysfunction: a randomized, double-blind study. J Thorac Cardiovasc Surg. 120: 642-50.

Rowe G, Manson N, Caplan M. 1983. Hydrogen peroxide and hydroxyl radical mediation of inactivated leucocyte depression of cardiac sarcoplasmic reticulum: Participation of the cyclooxigenase pathway. Circ Res. 53:584-91.

Sato H, Zhao ZQ, Jordan J. 1997. Basal nitric oxyde expresses endogenous cardio protection during reperfusion by inhibition of neutrophil mediated damage after surgical revascularization. J Thorac Cardiovasc Surg. 113:379-89

Sawa Y, Matsuda H, Shimzaki Y, Kaneko M, Nishimura M, Amemiya A, Sakai K, Nakano S. 1994. Evaluation of leukocyte-depleted terminal blood cardioplegic solution in patients undergoing elective and emergency coronary artery bypass grafting. J Thorac Cardiovasc Surg. 108:1125-31.

Suzuki I, Ogoshi N, Chiba M, Komatsu T, Moizumi Y. 1998. Clinical evaluation of a leukocyte-depleting blood cardioplegia filter (BC1B) for elective open-heart surgery. Perfusion. 13: 205-10.

Tomoeda H. 1999. Effects of leukocyte-depleted warm blood cardioplegia on cardiac and endothelial function. Kurume Med J. 46: 31-38.

Uyar I, Mansuro lu D, Kirali K, Erentu V, Bozbu a NU, Uysal G, Yakut C. 2005. Aspartate and glutamate-enriched cardioplegia in left ventricular dysfunction. J Card Surg. 20(4):337-44.

Vinten-Johansen J, Yellon DM, Opie LH. 2005. Postconditioning: a simple, clinically applicable procedure to improve revascularization in acute myocardial infarction. Circulation 112: 2085-2088.

Wilson I, Gardner TJ, DiNatalle CM. 1993. Temporary leucocyte depletion reduces ventricular disfunction during prolonged postischemic reperfusion. J Thorac Cardiovasc Surg. 106:805-810.

Yazicioglu Y, Erdogan S. 2004. SPSS Uygulamalı Bilimsel Arastirma Yöntemleri. Detay Yayinlari, Detay Yayincilik, ISBN: 975-8326-98-8. Page 324. 